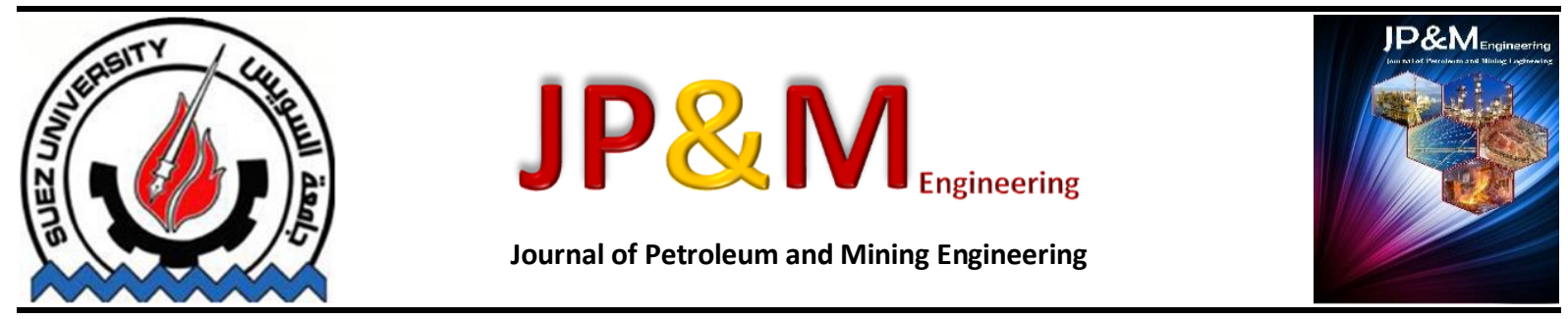

\title{
Reservoir Pressure Determination Using “After Hydraulic Fracturing Closure Analysis" technique
}

\author{
Hamed M. Khataba, Mahmoud A. Tantawy ${ }^{a}$, Ahmed A. Gawish ${ }^{a}$, Eslam H. Mahmoud \\ aFaculty of Petroleum and Mining Engineering, Suez University \\ ${ }^{b}$ Qarun Petroleum Company - Egypt
}

\begin{abstract}
The pressure of a reservoir is one of the most important parameters that is needed to calculate the hydrocarbon accumulation. Once the reservoir pressure is estimated, the fluid properties can be obtained via different correlations. Combined with the reservoir bulk volumes, the hydrocarbons in-place and recovery factor can be easily calculated. Consequently, if the estimate of the reservoir pressure is not accurate enough, it will be extremely difficult to determine the type of fluid we are dealing with; either saturated or undersaturated oil reservoir. In addition, it will be very challenging to accurately forecast production performance. During the last decades, the technology of Hydraulic fracturing plays one of the most important rule in the petroleum industry. It has become the magic tool for many company to change the fields' status from non-economic to economic. The objectives of fracturing low permeability reservoirs and high permeability reservoirs are variant and defined by reservoir parameters. Besides that, hydraulic fracture provides a new method to determine reservoir pressure and to estimate reservoir permeability, this method is called After Closure Analysis (ACA) Technique. ACA is one of the two analyses that are obtained by performing a Calibration Test, which is usually done before executing main hydraulic job. The two main analyses of Calibration Test are Pre-Closure analysis, which is used to optimize the fracture design, and ACA to determine reservoir pressure and estimate reservoir permeability. This paper illustrates some real cases that show the reasons why ACA is considered a very reliable technique to accurately determine the reservoir parameters with no considerable amount of funds compared to other counterparts' traditional techniques; like wireline formation testing (WFT) and pressure transient analysis (PTA). Also the paper shows how extra cost and non-productive time can be avoided if the right parameters are gotten on the rig site.
\end{abstract}

\section{Introduction}

Reservoir pressure is defined as the pressure of fluids within the pores of a reservoir, usually hydrostatic pressure, or the pressure exerted by a column of fluid from the formation's depth to the sea level. When impermeable rocks such as shale form as sediments are compacted, their pore fluids cannot always escape and must then support the total overlying rock column, leading to anomalously high formation pressures. As reservoir pressure changes when fluids are produced from a reservoir, the pressure should be described by a specified name, which refers to the time of measurements. For a new field without any production history, the reservoir pressure is anomalously called the initial pressure and for field that had production history it is called the average reservoir pressure [1].

There are many methods used to estimate reservoir pressure. The most common methods are pressure transient analysis (like pressure build up) and wireline formation testing. Pressure buildup analysis describes the buildup in wellbore pressure with time after a well was shut in for a certain period of time. One of the critical objectives of this analysis is to determine the static reservoir pressure without waiting weeks or even months for the pressure to stabilize in the entire reservoir [2].

For Wireline formation testing, it uses a sonde that can be positioned at any selected depth along the formation to get accurate measurements of pressure and fluid type and limited production data. Wireline 
tests are usually performed in open hole by using a cable-operated formation tester and sampling tool anchored at depth while reservoir communication is established through one or more pressure and sampling probes. This method is used to provide a direct static formation pressure measurement [3]

Unfortunately, there are some restrictions appear from different perspectives, mainly operational and economical issues. For the operational side, tight reservoirs show highly risk issues for both build up pressure and wireline formation tests. As a long time is spent to reach a stabilization status. In addition, for wireline formation test there is a high risk of getting stuck with the tool. Moreover, extra operation rig cost is added, which sometimes makes the whole operation non-economic, compared with the ACA technique, specially for tight and depleted reservoir.

Regarding the new concept, it becomes fact that Hydraulic fracturing is an effective mean for enhancing well productivity and recoverable reserves, especially for low permeability reservoirs by creating conductive path through the tight formation. A successful fracturing treatment for a given well is hard to be designed because of the required multiple variables. The use of inaccurate reservoir variables to design treatments may lead to a poor well's productivity. For a typical hydraulic fracturing operation, mini-fracture treatment (called calibration test) is performed very often to determine some needed parameters to calibrate the stimulation design .Calibration test is generally designed to be performed without pumping proppant and preferred to be pumped using a non-wall building fluid, if the purpose to know the reservoir pressure and formation permeability. Therefore, it retains negligible conductivity when it closes. The pressure analysis of calibration test was first introduced by Nolte [4], as the analysis divided into two main category Preclosure and After-Closure analysis (ACA).The basic principles are analogous to those for pressure analysis of transient fluid in the reservoir [5].

The fracturing pressure analysis during injection, formation closure and after closure period provides a powerful tool to understand and improve the fracture treatment design. Pre-closure analysis provides information on fracturing treatment design parameters such as fluid leak-off behavior, estimated fracture dimensions, fluid efficiency and closure pressure. These parameters can be used to determine the adequate pad volume and the required frac fluid viscosity [6]. Fig. 1 shows a typical history of the calibration test from the start of pumping until the reservoir disturbance from the fracture back to the initial reservoir pressure [7].

The main objective of the study focuses on the last period of the pressure response, or the afterclosure response noted on the figure as "transient reservoir pressure near the wellbore.". The afterclosure pressure behavior is independent on the physical properties that control fracture propagation and counts only on the history of the fluid loss, the fracture length, and the reservoir parameters. The "late-time" behavior becomes pseudo-radial flow and provides reservoir transmissibility $(\mathrm{k} h / \mu)$ and initial reservoir pressure in a manner similar to more traditional methods for a well test [8]. The main objective of the study is to explain and evaluate AfterClosure technique for obtaining reservoir parameters with actual field cases study supported by operational and analytical steps. The second objective is to provide an actual comparison between the new method and the two conventional methods, pressure transient analysis and wireline formation testing, supported by actual field cases history.

\section{AFTER CLOSURE ANALYSIS CONCEPT OF CALIBRATION TEST}

The pressure during this period reflects the transient reservoir response to fracturing and is independent on the mechanisms governing fracture propagation. Its character is determined entirely by the response of a reservoir disturbed by the fluidleakoff process. During this period, the reservoir may initially exhibit formation linear flow followed by transitional behavior and finally long-term pseudoradial flow. Formation linear flow and pseudoradial flow are hereafter referred to simply as linear and radial flow, respectively. The after-closure response is similar to the behavior observed during a conventional well test of a propped fracture. Therefore, it supports an evaluation methodology analogous to the established principles of pressure transient evaluation[9].

The after fracture- closure application of radialflow has been comprehensively covered in two companion papers. The first paper by $\mathrm{Gu}$ et al. 2 focused on application aspects, and the second paper by Abousleiman et at. ) focused on theoretical aspects. As Gu et al have developed a method called "Impulse fracture" which is an injection test used to determine formation permeability. The test consists of a small-volume water injection to create a short fracture and a shut-in period afterwards to record pressure falloff. During the injection, a small volume of water is injected into the well, and a short fracture is created in the formation. During the shut-in period, the pressure falls off and the fracture closes. The pressure is recorded before and after the fracture closure. The late time pressure falloff date, after the closure, is used to deduce permeability and reservoir pressure [10].

\section{Linear, Transitional and Radial flow pressure:}

Fig. 2 shows the pressure response after fracture closing of un-propped fracture as the pressure difference $\Delta \mathrm{P}=\mathrm{P}(\mathrm{t})-\mathrm{Pi}$ is normalized with respect to its value at closure $\mathrm{P}(\mathrm{tc})-\mathrm{Pi}$. Also shows variation of log-log slope defined as $\mathrm{d}(\ln \llbracket \Delta \mathrm{P}) \rrbracket / \mathrm{d}(\mathrm{ln} \llbracket \mathrm{t}) \rrbracket$

.This slope is used to define the variation of flow regime over different time intervals. As shown in the Fig.2, linear flow regime exhibits half slope for the pressure difference and derivatives. For Radial flow, it's characterized by unit log-log slope if pressure 
difference and derivative plotted against time on loglog scale. Between the two main flow regimes there is transitional period [11].
Pseudo linear flow

There is similarity between reservoir transient and heat transfer because of diffusion process that

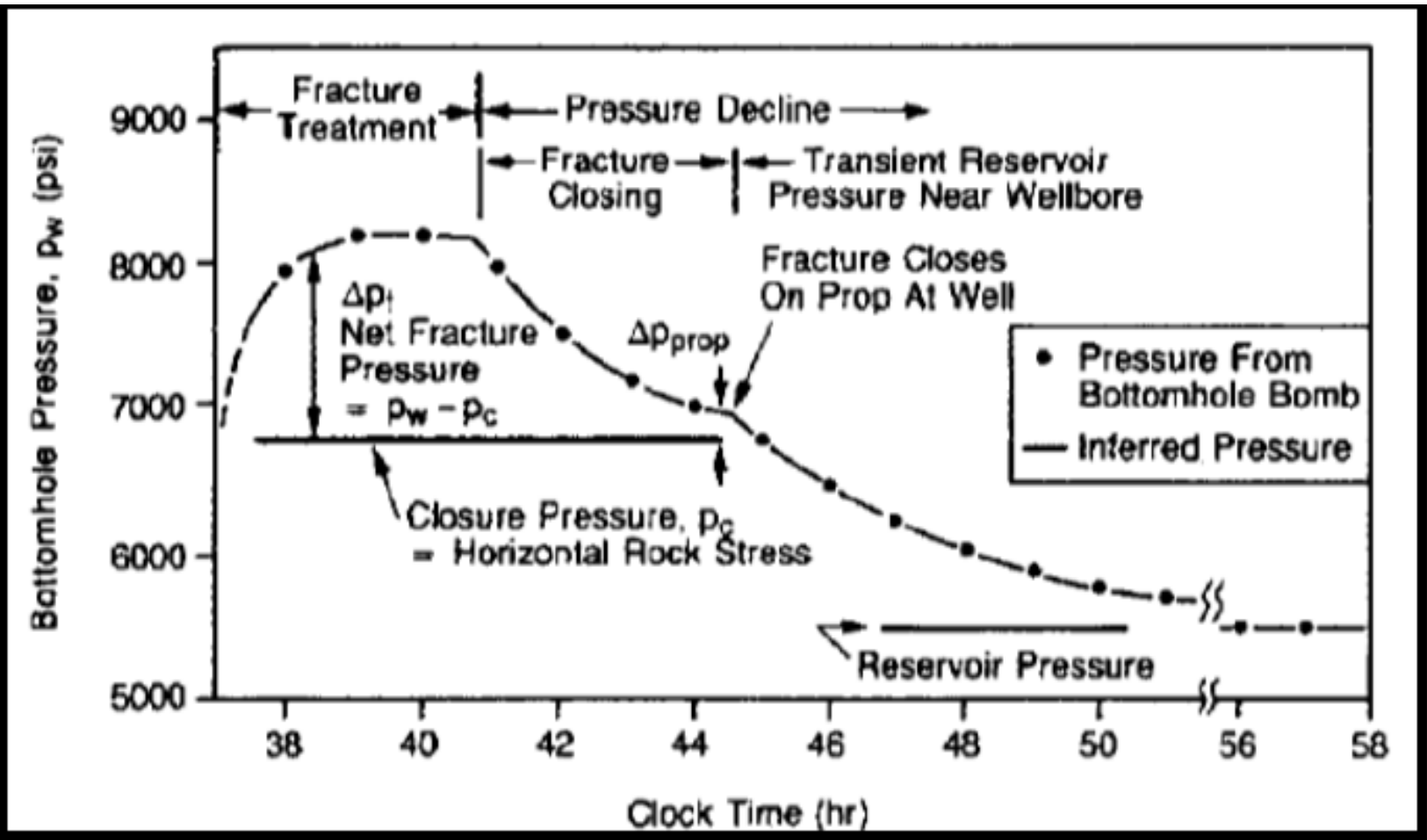

Figure 1 Typical History of Calibration test (Nolte[4][5]).

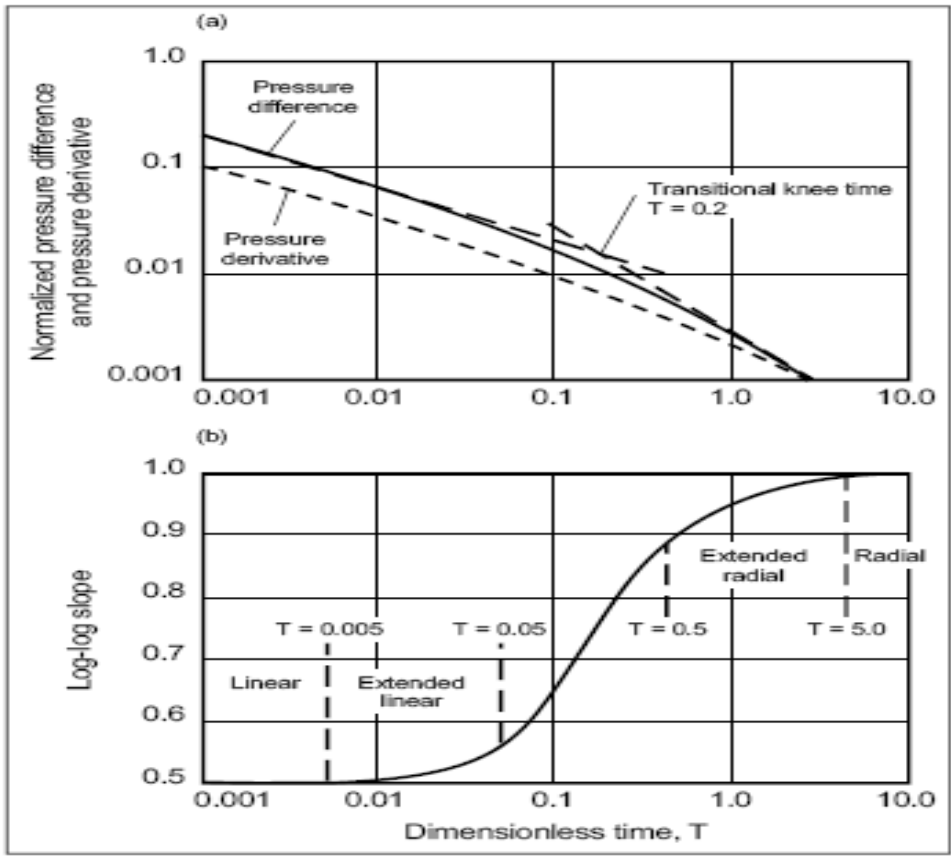

(a) and log-log slope (b) plots for an impulse injection[11]

Figure 2 After-Closure pressure difference and derivative

\section{Physical and Mathematical Descriptions:}

The Total pressure difference between fracture and reservoir divided into three component as shown in the Fig.3 but the related one to after closure analysis is $\triangle P R$ in the reservoir beyond the filtrate region (Invaded zone). governed the two physical phenomena and the physical concept of heat conductivity is similar to that of reservoir mobility.

The expression of pressure difference during linear flow period can be gotten from a similar condition presented by Carslaw and Jaegar (1959)[11]: 


$$
\begin{aligned}
\Delta \mathrm{PR} & =\mathrm{CL} \sqrt{\frac{\pi \mu}{\mathrm{K} \emptyset \mathrm{Ct}}} \\
& =\mathrm{CL} \sqrt{\frac{\pi \mu}{\mathrm{K} \emptyset \mathrm{Ct}}}\left\{\frac{2}{\pi} \sin ^{-1}\left(\sqrt{\frac{\mathrm{tc}}{\mathrm{t}}}\right)\right\} \\
& =\mathrm{CL} \sqrt{\frac{\pi \mu}{\mathrm{K} \varnothing \mathrm{Ct}}}\left\{\frac{2}{\pi}\left(\sqrt{\frac{\mathrm{tc}}{\mathrm{t}}}\right)\right\}
\end{aligned}
$$

Where:

- $\Delta \mathrm{PR}$ : the difference in pressure for linear flow

- tc : the closure time

- $\mathrm{t}$ : the time since fracture initiation

- $\mu$ : the fluid viscosity

- $\mathrm{k}$ : the formation permeability

- $\varnothing \quad$ : the formation porosity

- $\mathrm{C}_{-} \mathrm{t}$ : the formation total compressibility

- CL : the fluid-loss coefficient

The flow pattern of linear flow period is graphically described in Fig.4, the stream lines are linearly flow through the reservoir.

\section{Pseudo Radial flow}

Similar to linear flow behavior, pseudo radial flow behavior has mathematical expression to describe pressure drop during it as follow:

$$
\begin{aligned}
\Delta P(t) & =\frac{\mu}{2 \pi k h} \frac{V i}{t c}\left\{\frac{1}{2 \lambda} \ln \left(\frac{\lambda t c+(t-t c)}{t-t c}\right)\right\} \\
& \approx \frac{\mu}{4 \pi k h} \frac{V i}{t-t c} \quad t-t c \gg \lambda t c
\end{aligned}
$$

$$
\mathrm{t}=\mathrm{tc}
$$$$
\mathrm{t}>\mathrm{tc}
$$$$
t>3 t
$$

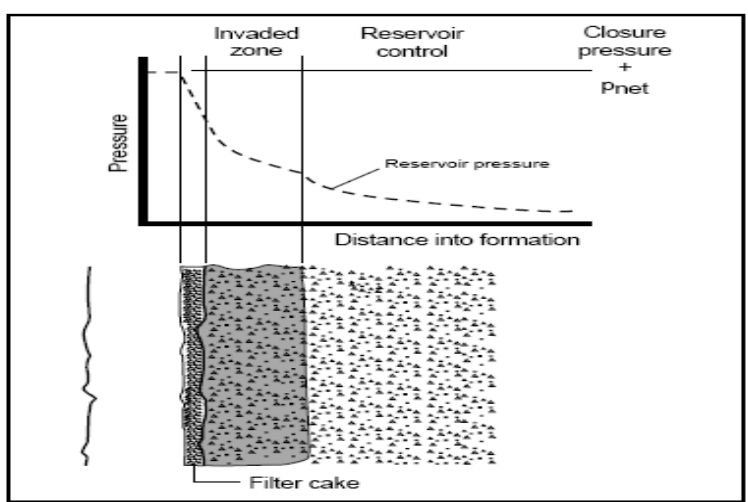

Figure 3 The three regions of fluid loss between fracture and reservoir[11].

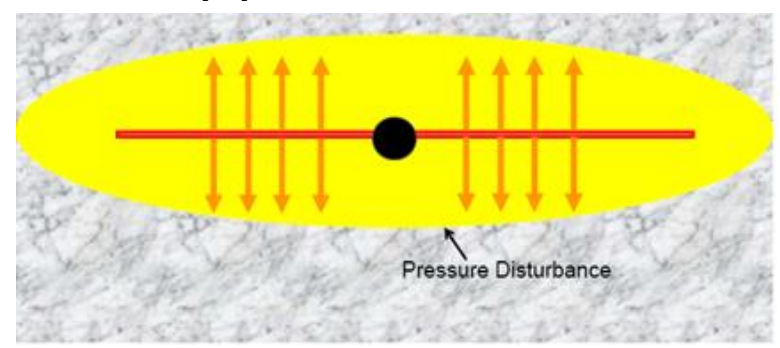

Figure 4 Flow pattern of linear flow period for after fracture closure[12].

$\&$

$$
\frac{1}{2 \lambda} \ln \left(1+\frac{\lambda t c}{t-t c}\right) \approx \frac{\pi^{2}}{8}\left\{\frac{2}{\pi} \sin ^{-1}\left(\sqrt{\frac{\mathrm{tc}}{\mathrm{t}}}\right)\right\}^{2}(1+\varepsilon) .
$$

Where:

- Vi : the volume of injected fluid

- $\mathrm{h}$ : the formation thickness

- $\lambda \quad$ : the multiplier was selected from numerical simulations as the value that provides the shortest after-closure time for the application

- $\varepsilon$ : is the error introduced by the approximation. The flow pattern of Radial flow period is typical described graphically in Fig.5, the stream lines are radially flow through the reservoir [11].

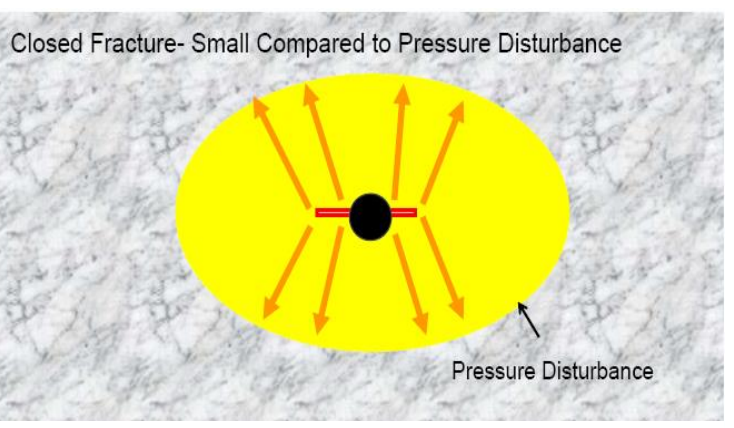

Figure 5 Flow pattern of Radial flow period for after closure [12]. 


\section{Consistent after-closure diagnostic framework:}

The theoretical relations outlined in the previous sections can be readily distilled into an elementary set of equations. These simplified relations provide a consistent framework for analyzing after-closure behavior and are summarized in this section.

\section{Linear flow}

Pseudo Linear flow pressure difference can be expressed by the following equation[11]

$\Delta P(t)=P(t)-P i=\operatorname{mlf}\{F L(t / t c)\}$

where $\mathrm{FL}(\mathrm{t} / \mathrm{tc})$ is the linear flow time function and mlf is the corresponding slope on a Cartesian plot:

$F L=\left\{2 / \pi \sin ^{\wedge}(-1)(\sqrt{ }(\mathrm{tc} / \mathrm{t}))\right\}$

And the slope

$$
\mathrm{mlf}=\mathrm{CL} \sqrt{(\pi \mu /(\mathrm{K} \emptyset \mathrm{Ct}))}
$$

\section{Radial flow}

Equation (1-2) provides the general expression of the logarithmic time function that describes the reservoir pressure difference during radial flow. This function can be approximated by the square of its linear flow counterpart (1-5) by introducing a coefficient of $\pi 2 / 8[11]$ :

$$
\frac{1}{2 \lambda} \ln \left(1+\frac{\lambda t c}{t-t c}\right) \approx \frac{\pi^{2}}{8}\left\{\frac{2}{\pi} \sin ^{-1}\left(\sqrt{\frac{\mathrm{tc}}{\mathrm{t}}}\right)\right\}^{2}(1+\varepsilon)
$$

Where:

- $\varepsilon$ is the error introduced by the approximation.

The radial flow period can then be represented by substituting the approximation provided by Eq. (1-7) into Eq. (1-2):

$$
\Delta P(t)=P(t)-P i=\operatorname{mrf}\{F L(t / t c)\}^{2} .
$$

where the function $\mathrm{FL}(\mathrm{t} / \mathrm{tc})$ is defined in Eq. (1-5) and $\mathrm{mrf}$ is the corresponding slope on a Cartesian plot:

$$
m r f=\frac{\pi}{16} \frac{V i \mu}{k h t c} .
$$

So, if we plot $\mathrm{P}(\mathrm{t}) \forall s\{F L(t / t c)\}^{2}$ on Cartesian plot we get intercept of $\mathrm{Pi}$ and slope include $\mathrm{K} / \mu$ which is mobility[11].

\section{GUIDELINES FOR AFTER-CLOSURE ANALYSIS FIELD APPLICATION}

The reservoir response during linear flow and either radial or transitional flow is required to conduct a comprehensive analysis of the after-closure period. The calibration testing sequence must be designed to provide a suitable pressure data. The following guidelines increase the likelihood of obtaining a comprehensive objective after-closure analysis:

- The reservoir pressure should ideally be equal to or greater than the hydrostatic pressure of the wellbore fluid also wellbore must be free of gas to ensure the communication along the wellbore to get real data and analysis.

- The objectivity of after-closure analysis can be improved by obtaining an a priori estimate of the reservoir pressure, and it's estimate can be obtained

$\checkmark$ as the stabilized bottomhole pressure measured prior to fluid injection into the reservoir

$\checkmark \quad$ as the stabilized surface pressure measured prior to fluid injection into an overpressured

$\checkmark \quad$ reservoir

$\checkmark$ from the surface pressure and hydrostatic column estimated through an accurate measurement of the fluid injected to completely fill the wellbore for an underpressured reservoir

$\checkmark \quad$ from an accurate reservoir pressure gradient established for the field.

- In deep or hot reservoirs, bottomhole gauges are necessary because wellbore fluid expansion from the decreasing pressure and increasing temperature during shut-in decrease the hydrostatic pressure.

- Volume has a minimal effect on dimensionless time and hence the time for development of radial flow because of the quasistationary value of dimensionless time for a constant injection rate. However, a minimum volume must be pumped to ensure an accurate measure of the volume injected through the perforations because the transmissibility is proportional to the injected volume (Eq. 1-9).

- If polymer fluids are used the pressure data obtained after fracture closure can be corrupted by continued consolidation (i.e., squeezing) of the fracture faces and filter cake.

These guidelines for the shut-in time increase the likelihood that adequate, representative pressure data are obtained for a valid after-closure analysis[11]. 


\section{FIELD CASE STUDY-OPERATIONS WERE APPLIED ON THE WELL, THE MAIN DATA AND RESULTS}

\section{Field Case 1: Well \#1 - Comparison between ACA and WFT}

\section{Well Completion and main data}

The completion procedure for the well includes 7" cemented liner across the reservoir section with 3.5 EUE tubing with PKR which is set on the same liner. The reservoir was perforated through wireline casing gun with (5 SPF,0.47" EHD \& 43" penetration). For calibration test, bottomhole pressure gauges were placed at the end of the above string with $150 \mathrm{ft}$ above the reservoir section. This sand stone reservoir is characterized by moderate permeability and porosity contaminated with silt streaks. The reservoir contains oil of $5 \mathrm{cp}$ viscosity and water of Sw ranged from 35:50 $\%$ see table- 1 and figure- 6 .

Table 1 The main reservoir properties test with brine water $4 \% \mathrm{KCL}$ and was pumped with 5 $\mathrm{bpm}$ injection rate. The pressure was monitored after shutting down until reaching stabilization. WFT estimated reservoir pressure value can be used to measure the reservoir pressure gradient as it appears to be $0.597 \mathrm{psi} / \mathrm{ft}$, which means that brine water with $4 \% \mathrm{KCL}$ is underbalance process $(0.44 \mathrm{psi} / \mathrm{ft}$ ).

After Mini fall-off test that used to conduct After Closure Analysis (ACA), Calibration test with X-linked gel was conducted to ensure the main fracture design and get the fracturing parameters then the main treatment was performed and the well was cleaned out after that the well was put on production.

\section{The Main Test Data and Results}

The main results of the Pre-Closure analysis can be found in table- 2 as the associated injection plot can be found in Figures 7 as the balanced fluid column makes easy to have continues WHP to calculate the downhole pressure which makes it easy to perform

\begin{tabular}{|l|l|l|l|}
\hline Reservoir Depth,TVDSS & $4570 \mathrm{ft}$ & Gross Height & $23.5 \mathrm{ft}$ \\
\hline Reservoir Temperature & $160^{\circ} \mathrm{F}$ & Net Height & $17.5 \mathrm{ft}$ \\
\hline WFT Reservoir Pressure & $2700 \mathrm{Psi}$ & Average Porosity & 0.255 \\
\hline WFT Reservoir Mobility & $3 \mathrm{md} / \mathrm{cp}$ & Average Water Saturation & 0.424 \\
\hline Fluid Compressibility & $7 \times 10^{-6} 1 / \mathrm{psi}$ & Reservoir Oil Viscosity & $5 \mathrm{cp}$ \\
\hline Inclination & $3^{\circ}$ & Total Depth ,TVSS & $5153 \mathrm{ft}$ \\
\hline
\end{tabular}

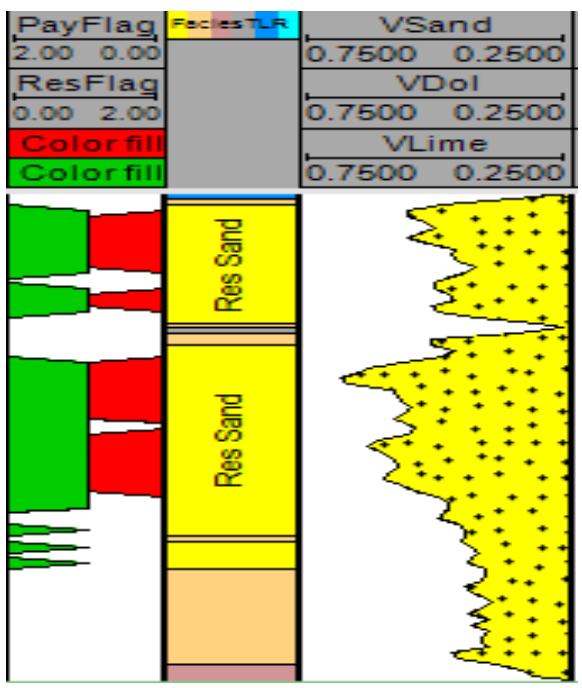

Figure 6 processed data for $\mathrm{OHL}$

\section{Operations were applied on the well}

During drilling phase, RDT job was performed to record the reservoir pressure and obtain the reservoir mobility. After that the reservoir was perforated through wireline casing gun then perform Mini fall-off
PCA and get closure pressure and other fracturing parameters, see G-function plot Figure 8.

For After-closure period, the Log-Log plot which shows different flow regimes can be found in Figure 9 , it is easy to see the unite slope from this plot which represent the pseudo radial flow and reservoir behavior. FR plot as in Figure 10 shows the determination of reservoir pressure from the intercept of the straight line with $\mathrm{Y}$-axis and the slope uses to get reservoir transmissibility. All the ACA results can be found in Table-3.

Firstly, note that the reservoir pressure required to match the ACA is $2730 \mathrm{psi}$ and recall that the WFT measurement for reservoir pressure was taken over 7 data points on $17.5 \mathrm{ft}$ net thickness, showed 2715 psi table-4. By continuing the analysis of the after closure period data through $F R$ plot it's found that the following results $\mathrm{kh}=760 \mathrm{md} / \mathrm{cp}$ with Hnet $=17.5 \mathrm{ft}$, which gives $k=43 \mathrm{md}$. These results show good match with those obtained from WFT according to table- 5 pressure and permeability from WFT are 2715 psi and $40 \mathrm{md}$ respectively and from ACA are 2730 psi and 43 $\mathrm{md}$. All these data approve the reaching of radial flow regime through the after closure period. 
Table 2 Pre-Closure Analysis Results

\begin{tabular}{|c|c|c|}
\hline Pumping time, Hrrs. & 0.098 & $|S|$ PPSi \\
\hline Pumping Volume,STB & 118.3 & Fratcure Effciency,y \\
\hline Closurue Pressure, Psi & 3663.75 & G. function Slope, Psi \\
\hline Closure Time, Hirs. & 0.039 & Closure G-VIave \\
\hline
\end{tabular}

Table 3 After-Closure Analysis Results.

\begin{tabular}{|l|l|l|l|}
\hline Start of linear flow, Hrs. & 0.04 & Far field mobility, md/cp & 46 \\
\hline End Linear Flow, Hrs. & 2.1 & Flow Capacity “ KH”, md.ft & 760 \\
\hline Start of radial flow, Hrs. & 3.16 & Permeability, md & 43 \\
\hline Reservoir initial pressure & 2730 & Fracture half length ,ft & 37 \\
\hline
\end{tabular}

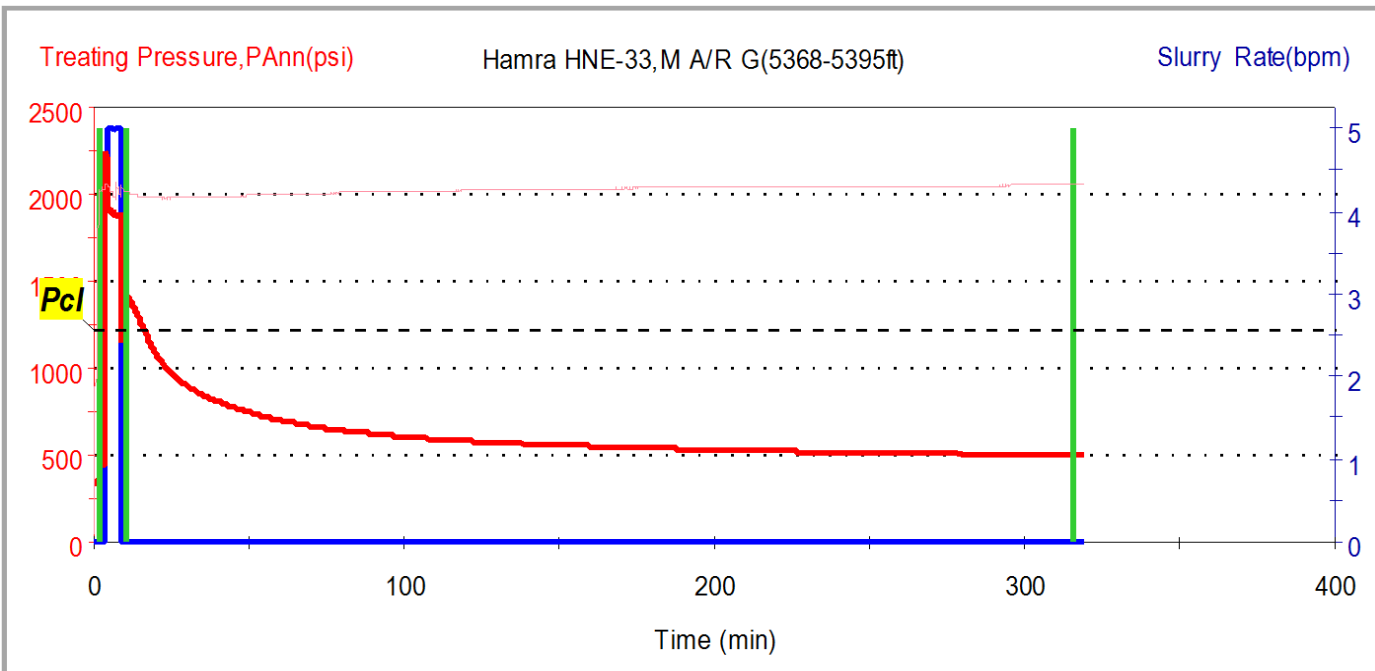

Figure 7 Injection Plot.

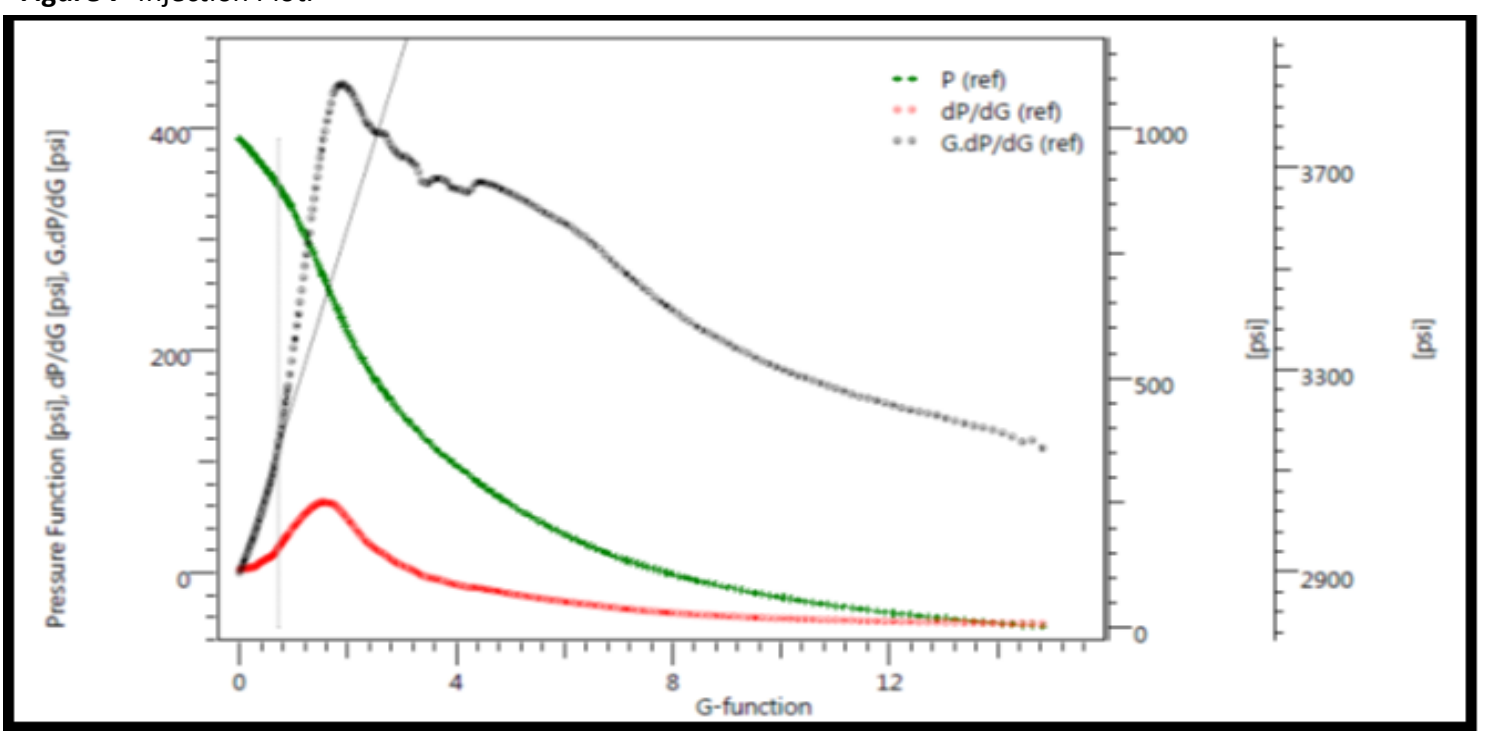

Figure 8 G- Function Plot

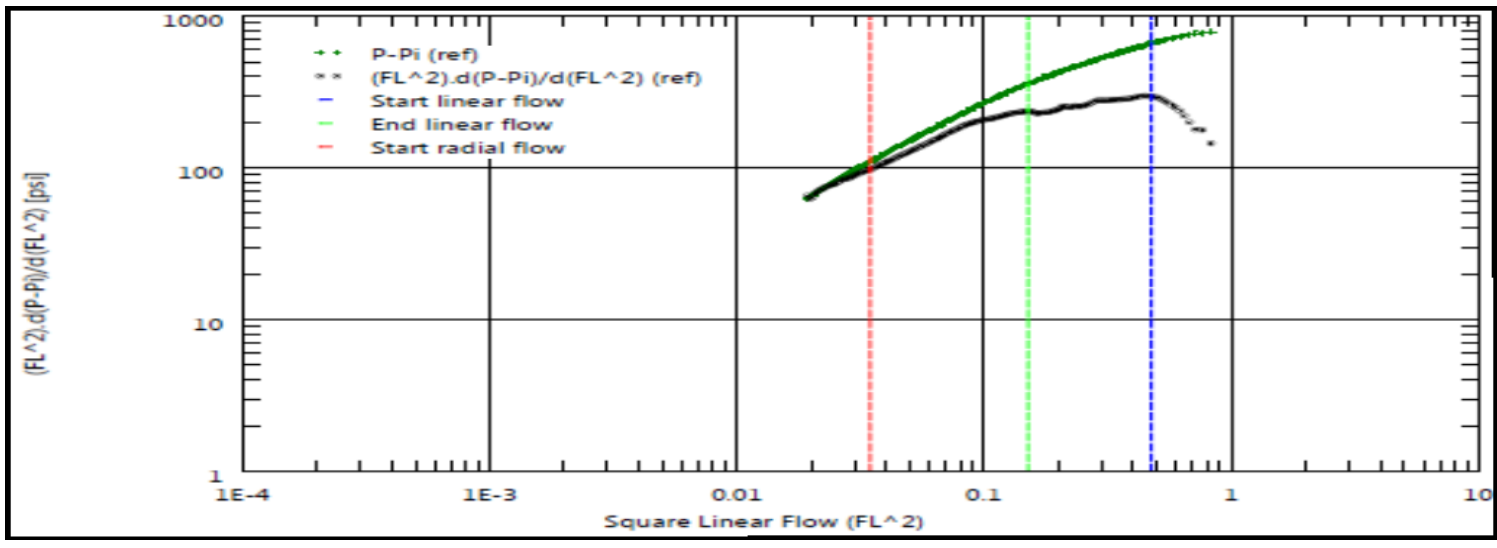

Figure 9 Log-Log Plot. 


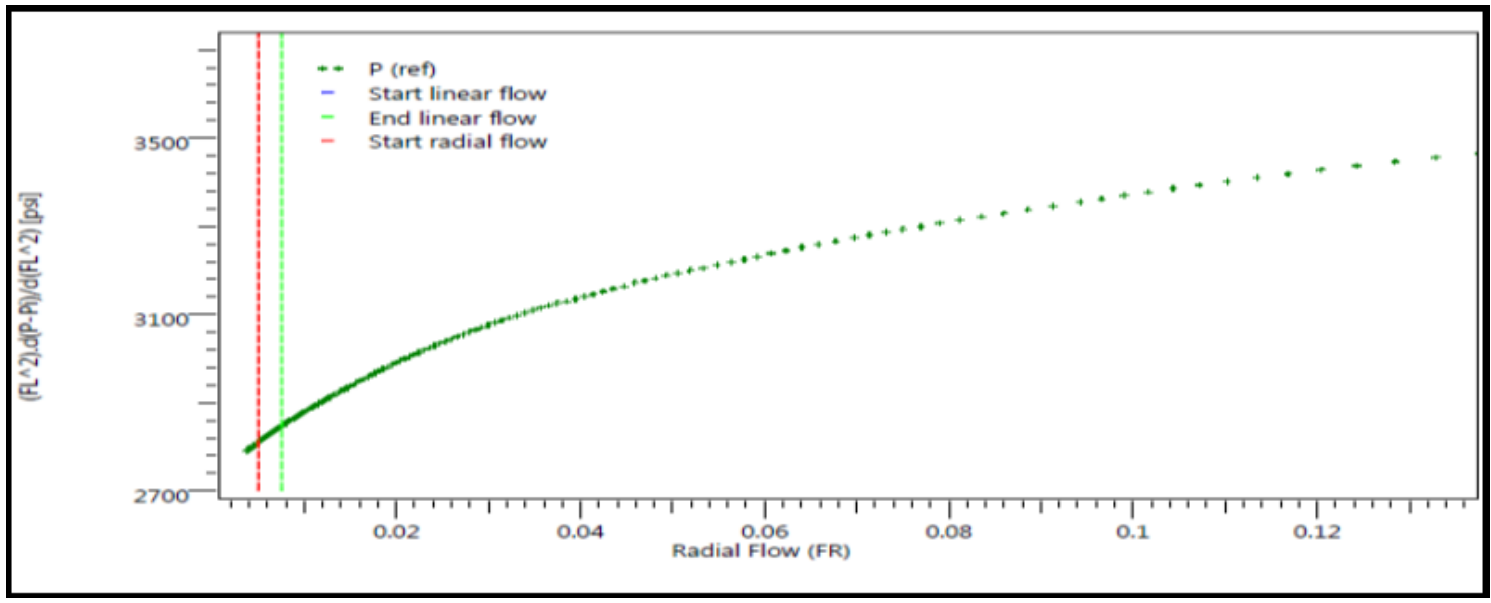

Figure 10 FR Plot.

Table 4 WFT Results

\begin{tabular}{|c|c|c|c|c|c|c|}
\hline Depth & \multicolumn{2}{|c|}{ Hydrostatic Press. } & Shut in Press & Temp. & Mobility & \multirow{2}{*}{ Comments } \\
\cline { 1 - 4 } FT & Before & After & $(p s i)$ & F & md/cp & \\
\hline 53392 & 2711 & 2710 & 2718.6 & 147 & 4.51 & NORMAL TEST \\
\hline 53390 & 2709 & 2709 & 2715.6 & 147 & 3.33 & NORMAL TEST \\
\hline 5386 & 2712 & 2712 & 2718.7 & 148 & 2.06 & NORMAL TEST \\
\hline 5384 & 2710 & 2710 & 2716.9 & 149 & 3.42 & NORMAL TEST \\
\hline 5377.5 & 2706 & 2706 & 2712.7 & 150 & $\mathbf{8 . 5 3 0}$ & NORMAL TEST \\
\hline $\mathbf{5 3 7 2}$ & 2702 & 2702 & 2706.8 & 151 & $\mathbf{0 . 7 3}$ & NORMAL TEST \\
\hline $\mathbf{5 3 7 0}$ & 2700 & 2700 & 2707.6 & 151 & $\mathbf{3 . 0 2 0}$ & NORMAL TEST \\
\hline
\end{tabular}

Table 5 Comparison between ACA and WFT results.

\begin{tabular}{|l|c|l|c|}
\hline \multicolumn{1}{|c|}{ WFT } & Value & \multicolumn{1}{c|}{ ACA } & Value \\
\hline Res. Pressure, psi & 2715 & Res. Pressure ,psi & 2730 \\
\hline Aver. Mobility, md/cp & 58 & Mobility,md/cp & 46 \\
\hline Aver. Permeability, md & 40 & Permeability ,md & 43 \\
\hline
\end{tabular}

Economic and Cost evaluation for ACA compared with WFT:

Concerning the economic evaluation of ACA technique, it contains two main items. One item is the time of the operations on the rig while the other one is service cost .According to table- 6 , the cost of the rig time for all the operation of ACA is nearly $30 \%$ of rig time cost for all operation of WFT. Also the same issue for the service cost of ACA is nearly $10 \%$ of WFT service cost. This data gives us one conclusion that the total cost of ACA is nearly $20 \%$ from the cost of WFT which means that ACA is cheaper and more accurate than WFT. 
Table 6 Economic evaluation

\begin{tabular}{|l|c|}
\hline \multicolumn{1}{|c|}{ Item } & Ratio (ACA/WFT),\% \\
\hline Rig time cost & 31 \\
\hline Service cost & 11 \\
\hline Total cost & 19 \\
\hline
\end{tabular}

Field Case 2: Well \#2 - Comparison between ACA and PTA

\section{Well Completion and main data}

The completion procedure for the well include 7" cemented liner over the reservoir section with 3.5 EUE tubing with PKR which is setting in the same liner. The reservoir was perforated through wireline casing gun with (5 SPF,0.47" EHD \& 43" penetration). For each of the calibration and pressure transient test, bottomhole pressure gauges were placed at the end of the above string with $200 \mathrm{ft}$ above the reservoir section. This sand stone reservoir is characterized by low permeability and porosity contaminated with silt streaks. The reservoir contains oil of $5 \mathrm{cp}$ viscosity and water of Sw ranged from 35:50 \% see table-7 and figure-11.

Table 7 The main reservoir properties

\begin{tabular}{|c|c|c|c|}
\hline Reservoir Depth,TVDSS & $4402 \mathrm{ft}$ & Gross Height & $26.5 \mathrm{ft}$ \\
\hline Reservoir Temperature & $160^{\circ} \mathrm{F}$ & Net Height & $24 \mathrm{ft}$ \\
\hline Total Depth ,TVDSS & $4957 \mathrm{ft}$ & Average Porosity & 0.22 \\
\hline Fluid Compressibility & $\begin{array}{c}7 \times 10^{-6} \\
1 / \mathrm{psi}\end{array}$ & Average Water Saturation & 0.34 \\
\hline Inclination & $20^{\circ}$ & Reservoir Oil Viscosity & $5 \mathrm{cp}$ \\
\hline
\end{tabular}

\section{Operations were applied on the well}

During drilling phase, RDT job wasn't performed due to bad hole condition. After that the reservoir was perforated through wireline casing gun then perform Mini fall-off test with brine water $4 \% \mathrm{KCL}$ and was pumped with $10 \mathrm{bpm}$ (14400 BPD) injection rate. The pressure was monitored after shutting down until reaching stabilization. Estimated reservoir pressure value from the offset wells can be used to know the reservoir pressure gradient as it appears to be 0.72 $\mathrm{psi} / \mathrm{ft}$, which means that brine water with $4 \% \mathrm{KCL}$ is underbalance process $(0.44 \mathrm{psi} / \mathrm{ft})$ and this high pressure gradient is due to injection effect from offset injector.

After Mini fall-off test that used to perform After Closure Analysis (ACA), Calibration test with X-linked gel was conducted to ensure the main fracture design and get the fracturing parameters then the main treatment was performed and the well was cleaned out after that build up pressure test was conducted to get reservoir properties. ACA and PTA results. ACA

\section{The Main Test Data and Results}

The main results of the Pre-Closure analysis can be found in table- 8 as the associated injection plot can be found in Figures 12 as the balanced fluid column makes easy to have continues WHP to calculate the downhole pressure which make it easy to perform PCA and get closure pressure and other fracturing parameters, see G-function plot Figure 13.

The Log-Log plot which shows different flow regimes can be found in Figure 14 , it is easy to see the unite slope from this plot which represent the pseudo radial flow and reservoir behavior. FR plot as in Figure 15 shows the determination of reservoir pressure from the intercept of the straight line with $\mathrm{Y}$-axis and the slope uses to get reservoir transmissibility. All the ACA results can be found in Table- 9

The main objective of PTA is to determine reservoir properties. Figure-16 present historical data of flowing and build up periods which shows some operational noisy through these periods. Log-Log analysis of the data showed good indication of radial flow regime with zero slope present in Figure-17 also semi-log analysis is performed to give kind of confirmation about the results figure-18. Table-10 gives complete summary about the reservoir properties and fracture geometry.

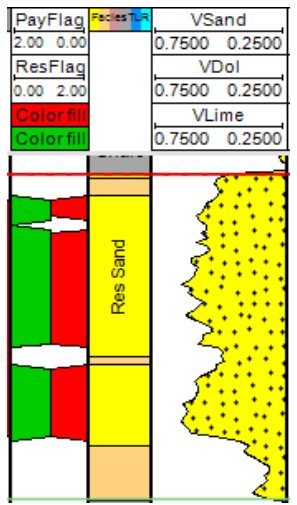

Figure 11 processed data for $\mathrm{OHL}$

From table-9 \& 10 we found that the reservoir pressure from the two tests nearly the same as from ACA Pr $=3206$ psi and from PTA Pr $=3240$ psi also by continuing the analysis of the after closure period data it's found the following results $k h=100 \mathrm{md}$. $\mathrm{ft}$ with Hnet $=24 \mathrm{ft}$, results in $\mathrm{k}=4 \mathrm{md}$ and for PTA it's found the following data $\mathrm{kh}=88 \mathrm{md}$. $\mathrm{ft}$ with Hnet $=24$ $\mathrm{ft}$, results in $\mathrm{k}=3.5 \mathrm{md}$, skin $=-3.5$ from Log Log Plot and from Semi-Log Plot it's found the following $k h=$ $97 \mathrm{md}$. ft with Hnet $=24 \mathrm{ft}$, results in $\mathrm{k}=3.9 \mathrm{md}$, skin= -3.47. Table-11 summarize the comparison between

\section{Economic and Cost evaluation for ACA compared with}

For Economic evaluation it's contain two main items, the first item is the time of the operation on the rig and the other is the service cost. According to table-12, it shows that the cost of the rig time for all the operation of ACA is nearly $18 \%$ from the cost of 
the rig time for all operation of PTA. Also the same issue for the service cost of ACA is nearly $12 \%$ from the service cost of PTA. All this data gives us one conclusion that the total cost of ACA is nearly $15 \%$ from the cost of PTA which mean that ACA is cheaper than PTA.

Table 8 Pre-Closure Analysis Results

\begin{tabular}{|l|c|l|c|}
\hline Pumping time ,Hrs. & 0.088 & ISIP ,Psi & 4365 \\
\hline Pumping Volume ,STB & 53 & Fracture Efficiency ,\% & 56 \\
\hline Closure Pressure ,Psi & 4004 & G-function Slope, Psi & 139 \\
\hline Closure Time ,Hrs. & 0.2 & Closure G- Vlaue & 2.6 \\
\hline
\end{tabular}

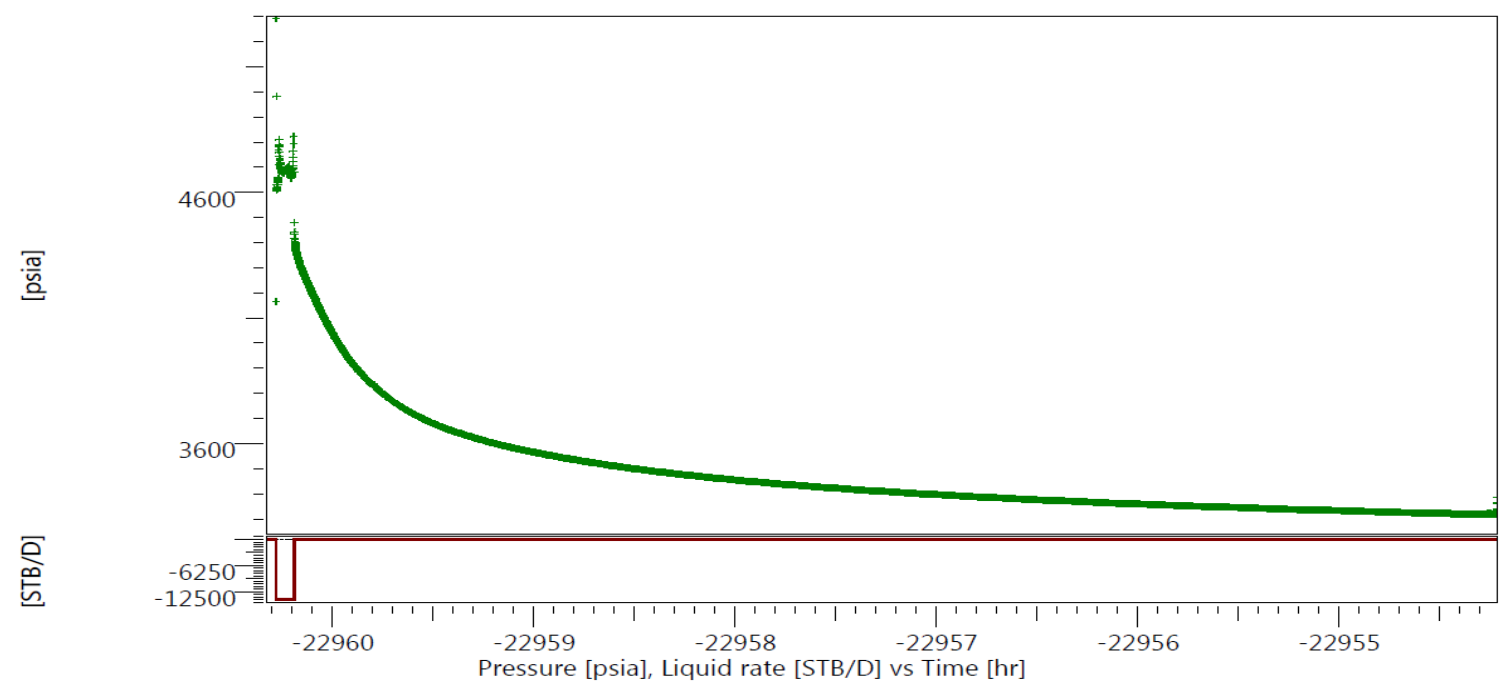

Figure 12 Injection Plot.

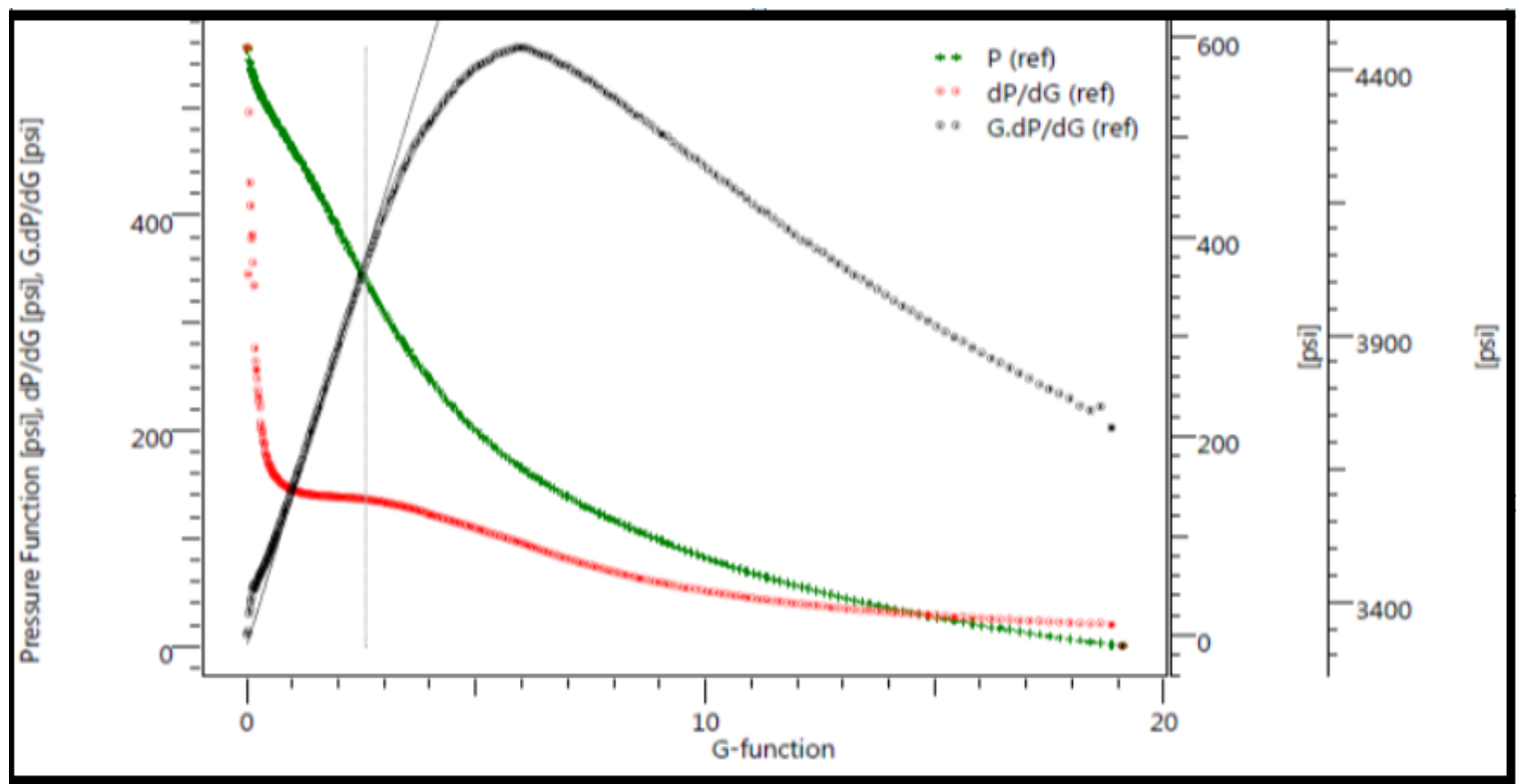

Figure 13 G- Function Plot 
Table 9 After-Closure Analysis Results.

\begin{tabular}{|l|c|l|c|}
\hline Start of linear flow ,Hrs. & 1.05 & Far field mobility, md/cp & 5.8 \\
\hline End Linear Flow , Hrs. & 1.88 & Flow Capacity “ KH”, md.ft & 100 \\
\hline Start of radial flow, Hrs. & 5.6 & Permeability, md & 4 \\
\hline Reservoir initial pressure & 3206 & Fracture half length, ft & 105 \\
\hline
\end{tabular}

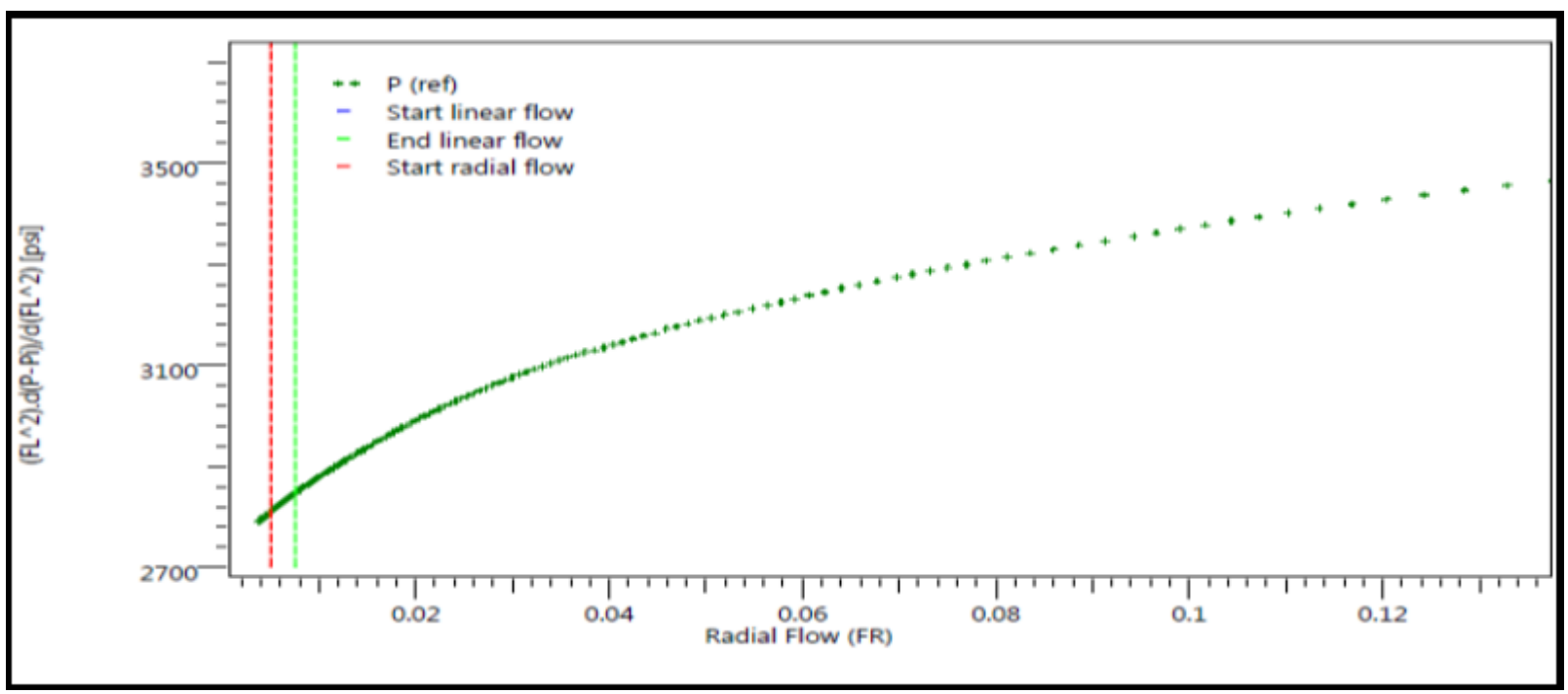

Figure 14 Log-Log Plot.

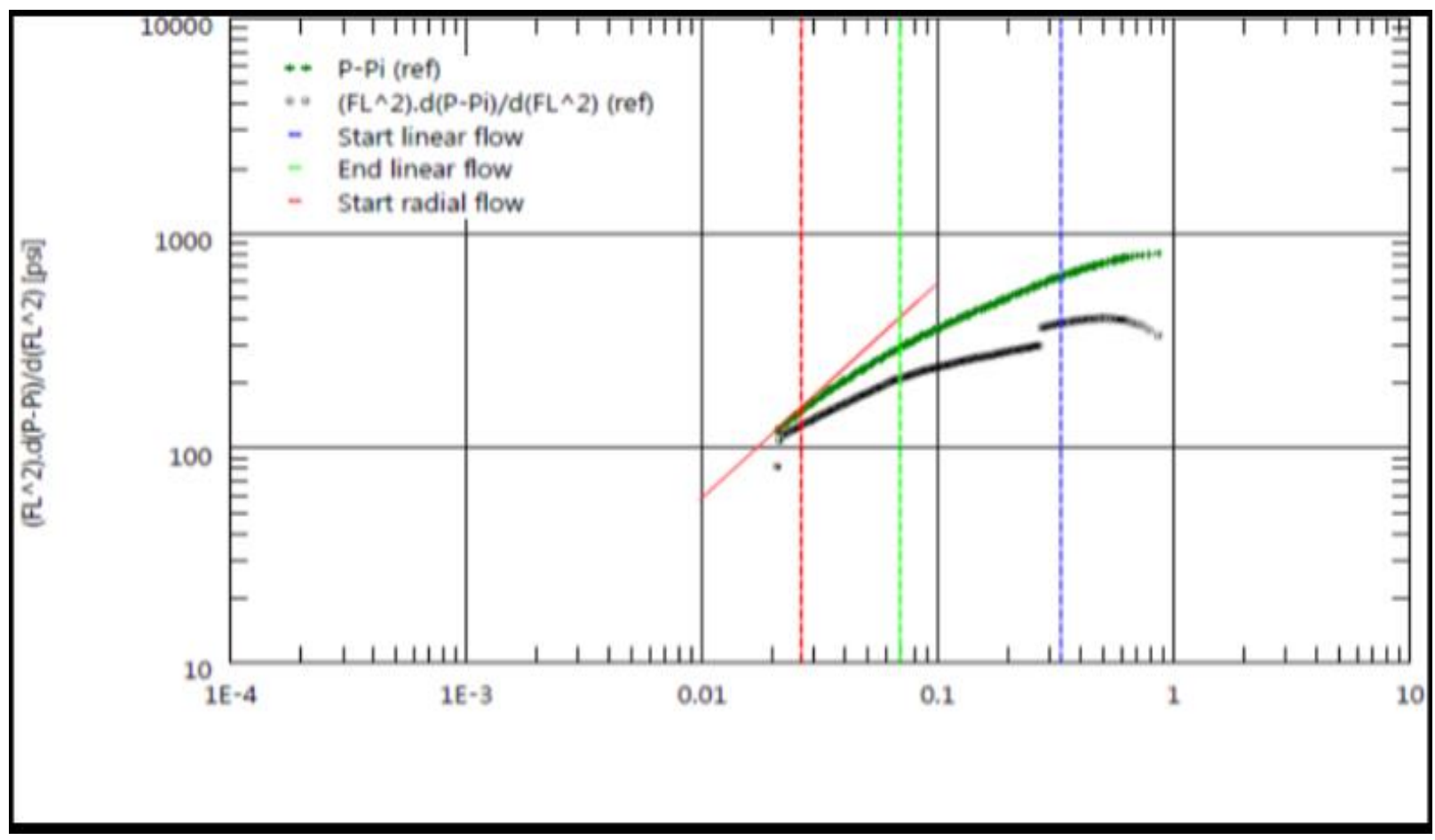

Figure 15 FR Plot. 
Table 10 Pressure Transient Analysis Results

\begin{tabular}{|l|c|l|c|}
\hline Reservoir pressure ,psi & 3240 & Reservoir permeability, md & 3.5 \\
\hline Skin & -3.5 & KH , md.ft & 88 \\
\hline Xf, ft & 32 & Semi log K, md & 3.9 \\
\hline Semi log Skin & -3.47 & Semi log p, psi & 3211 \\
\hline Smi log slop, psi & 1636 & Smi log KH, md.ft & 97 \\
\hline
\end{tabular}

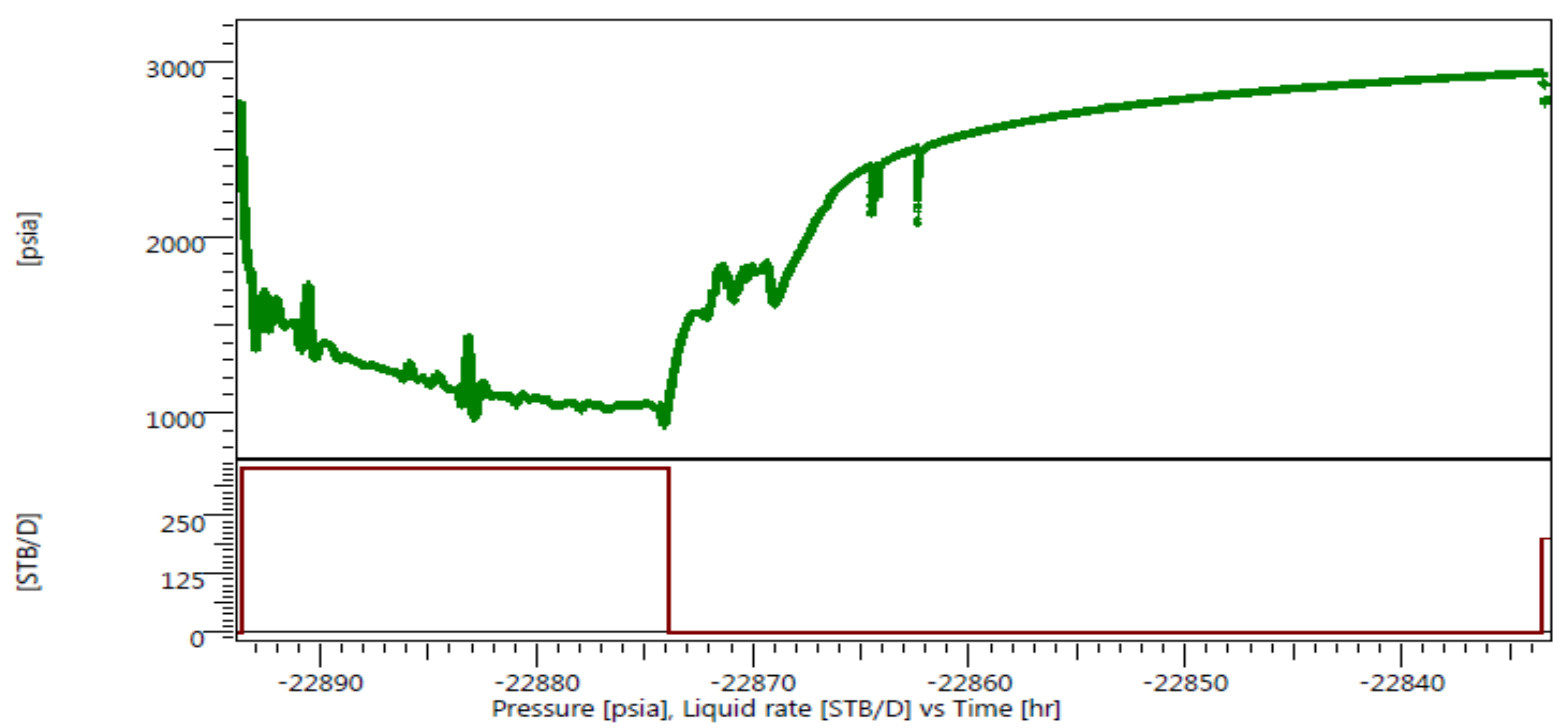

Figure 16 Historical data

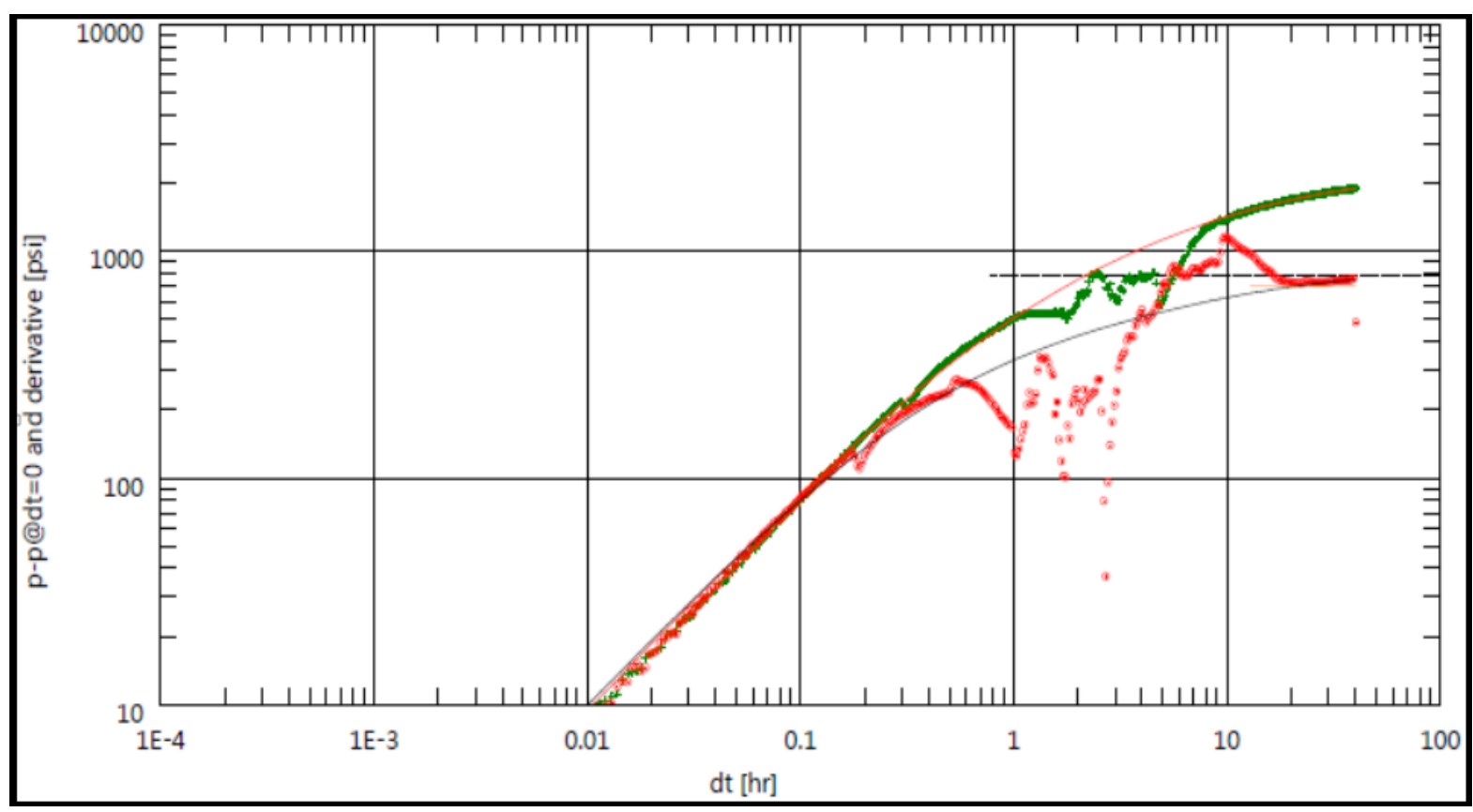

Figure 17 Log-Log Plot. 


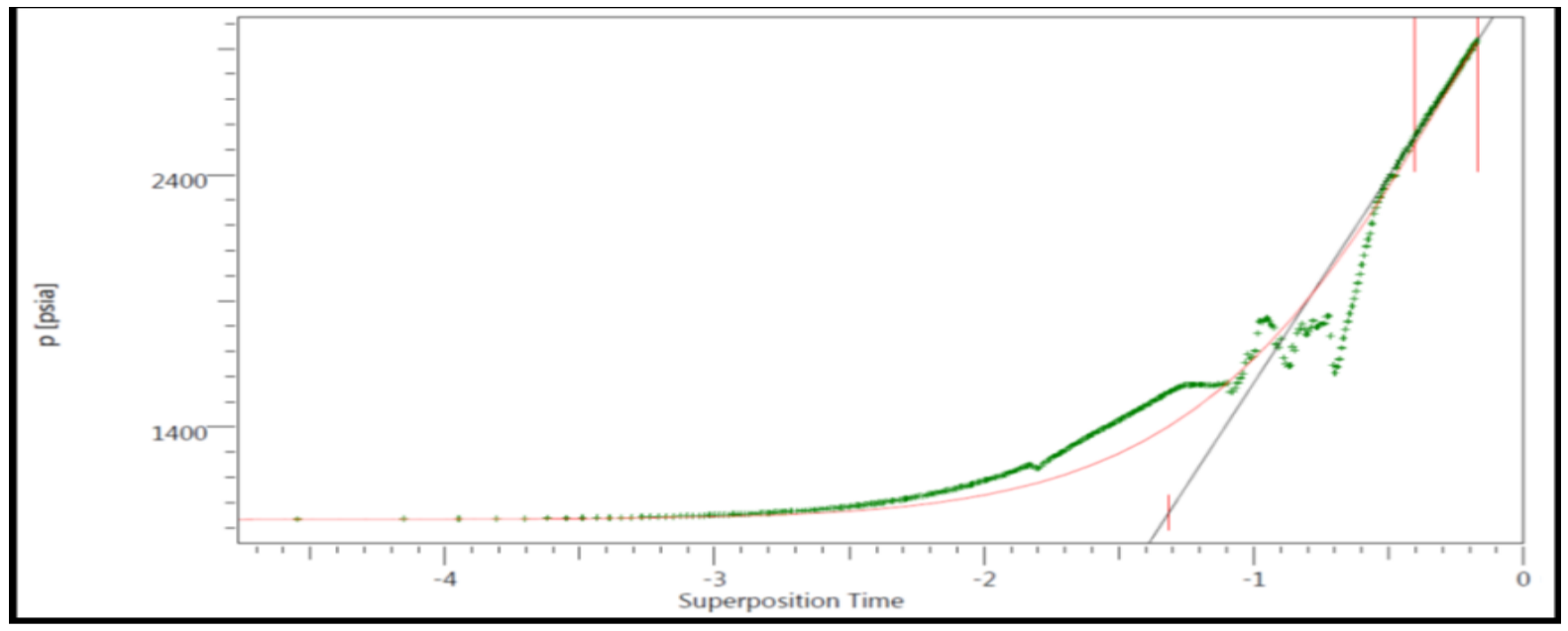

Figure 18 Semi-log Plot.

Table 11 Comparison between ACA and PTA results.

\begin{tabular}{|l|c|l|c|}
\hline \multicolumn{1}{|c|}{ PTA } & Value & \multicolumn{1}{|c|}{ ACA } & Value \\
\hline Res. Pressure,psi & 3240 & Res. Pressure,psi & 3206 \\
\hline $\mathrm{KH}, \mathrm{md} / \mathrm{cp}$ & 88 & $\mathrm{KH}, \mathrm{md} / \mathrm{cp}$ & 100 \\
\hline Permeability, md & 3.5 & Permeability, md & 4 \\
\hline
\end{tabular}

Table 12 Economic evaluation

\begin{tabular}{|l|c|}
\hline Item & Ratio (ACA/WFT),\% \\
\hline Rig time cost & 18 \\
\hline Service cost & 12 \\
\hline Total cost & 15 \\
\hline
\end{tabular}

\section{Field Case 3: Well \#3 - Application of ACA}

\section{Well Completion and main data}

The completion procedure for the well include 7" cemented liner over the reservoir section with 3.5 EUE tubing with PKR is setting in the same liner. The reservoir was perforated through wireline casing gun with (5 SPF, 720 phase, 0.47" EHD \& 43" penetration).For calibration test, bottomhole pressure gauges were placed at the end of the above string with $150 \mathrm{ft}$ above the reservoir section. This sand stone reservoir is characterized by moderate permeability and porosity contaminated with silt streaks. The reservoir contains oil of $5 \mathrm{cp}$ viscosity and water of Sw ranged from 35:50 \% see table-13 and figure-19.

Operations were applied on the well

During drilling phase, RDT job wasn't performed due to bad hole condition. After that the reservoir was perforated through wireline casing gun then perform Mini fall-off test with brine water $4 \% \mathrm{KCL}$ and was pumped with average injection rate15 bpm (21600 BPD). The pressure was monitored after shutting down until reaching stabilization. The reservoir pressure gradient is $0.72 \mathrm{psi} / \mathrm{ft}$, which mean that brine water with $4 \% \mathrm{KCL}$ is underbalance process $(0.44$ $\mathrm{psi} / \mathrm{ft}$ ) and this high pressure gradient is due to injection effect from offset injector. After Mini fall-off 
test that used to perform After Closure Analysis (ACA), Calibration test with $\mathrm{X}$-linked gel was conducted to ensure the main fracture design and get the fracturing parameters then the main treatment was performed and the well was cleaned out after that the well was put on production.

Table 13 The main reservoir properties values more accurate than WFT, as it has larger radius of investigation and the error not exceed $7 \%$.

- Based on Pressure transient analysis and AfterClosure data analysis results, it's found that ACA gives good results with an average error 3\% for reservoir pressure. And it gives permeability values nearly locate in the same range.

\begin{tabular}{|l|l|l|l|}
\hline Reservoir Depth,TVDSS & $4475 \mathrm{ft}$ & Gross Height & $21 \mathrm{ft}$ \\
\hline Reservoir Temperature & $166^{\circ} \mathrm{F}$ & Net Height & $18 \mathrm{ft}$ \\
\hline Total Depth ,TVDSS & $4975 \mathrm{ft}$ & Average Porosity & 0.26 \\
\hline Fluid Compressibility & $\begin{array}{l}7 \times 10^{-6} \\
1 / \mathrm{psi}\end{array}$ & Average Water Saturation & 0.38 \\
\hline Inclination & $5^{\circ}$ & Reservoir Oil Viscosity & $5 \mathrm{cp}$ \\
\hline
\end{tabular}

\section{The Main Tests Data and Results}

The main results of the Pre-Closure analysis can be found in table-14 as the associated injection plot can be found in Figures 20 as the balanced fluid column makes easy to have continues WHP to calculate the downhole pressure, perform PCA, get closure pressure and other fracturing parameters, see Gfunction plot Figure 21.

The Log-Log plot which shows different flow regimes can be found in Figure 22 , it is easy to see the unite slope from this plot which represent the pseudo radial flow and reservoir behavior. FR plot as in Figure 23 shows the determination of reservoir pressure from the intercept of the straight line with $\mathrm{Y}$-axis and the slope uses to get reservoir transmissibility. All the ACA results can be found in Table-15

\section{CONCLUSIONS AND RECOMMENDATIONS}

After the calculations that were performed to evaluate After Closure Analysis as new method to get reservoir pressure and estimate reservoir permeability and compare between it and the conventional techniques, we finally manage to reach a final conclusion that shows the main positive points of the new technology and the negative points.

\section{Conclusions that are drawn from this study}

- This paper introduces the technical concept for the analysis of the data recorded after formation closure and how we can use this data to get the main reservoir parameters, specially reservoir pressure and permeability.

- Providing the main guidelines and operational steps for the test and the analysis to get reservoir characteristics for sand stone reservoir with low and moderate permeability.

- Comparing between wireline formation testing and After-Closure Analysis, it's found that ACA gives good results with an average error less than $1 \%$ for reservoir pressure. Moreover it gives permeability

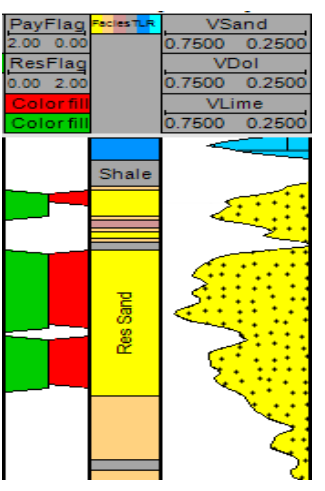

Figure 19 processed data for $\mathrm{OHL}$

- From both comparison in case 1 \& 2, it isn't doubtable that ACA is a reliable method to get reservoir parameters specially reservoir pressure and it's appeared in case 3.

- The time needed to reach pseudo radial flow is inversely proportional with the reservoir permeability which means long time is needed for low permeability reservoirs.

- The main limitations of ACA in depleted moderately permeable reservoirs. are the right selection of flow regimes and maintenance of fluid level in the well which ensure a valid data acquisition.

If polymer fluids are used, the pressure data obtained after fracture closure can be corrupted by the continuous consolidation of the fracture faces and filter cake.

Recommendations that were drawn from this study

- It's better to apply ACA in the well that planned to be hydraulically fractured specially for tight and depleted formation as the hydraulic fracture equipment already on site.

- In order to prevent the problems result from losing fluid level during falloff in depleted wells, be sure that downhole memory gauges are planned to be installed in order to record the pressure or using lighter fluid to injected after the treatment to maintain the level in wellbore.

- The calibration test should be planned allow for closure and enough fall-off time to enter linear and radial flow in order to enable getting reservoir parameters.

- It's recommended to use Newtonian non-wall building fluid to prevent any corruption in the results by existed polymers.

- According to the study, it's recommended to apply this techniques to get reservoir permeability as the main objective of this study which is getting reservoir pressure. 
Table 14 Pre-Closure Analysis Results

\begin{tabular}{|l|c|l|c|}
\hline Pumping time, Hrs. & 0.18 & ISIP,Psi & 4435 \\
\hline Pumping Volume, STB & 170 & Fracture Efficiency,\% & 41 \\
\hline Closure Pressure, PSi & 4186 & G-function Slope, Psi & 176 \\
\hline Closure Time, Hrs. & 0.2 & Closure G-Vlaue & 1.4 \\
\hline
\end{tabular}

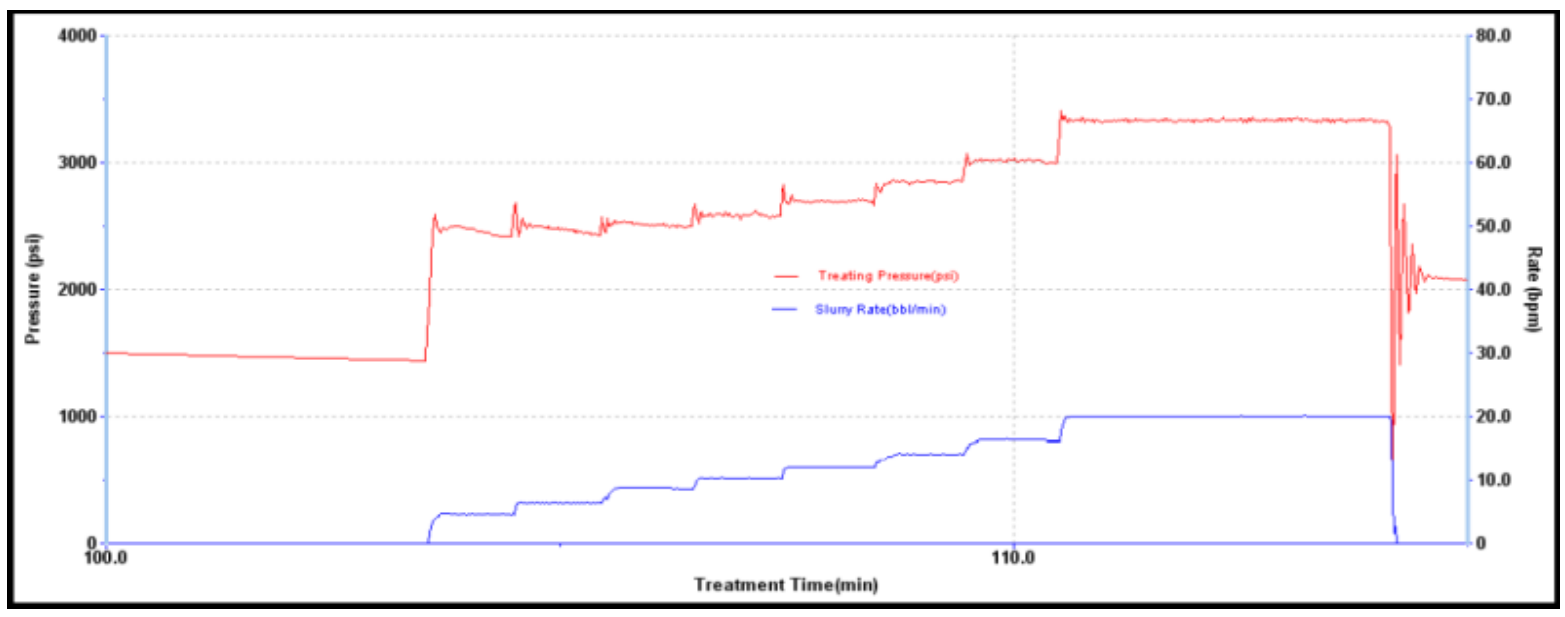

Figure 20 Injection Plot.

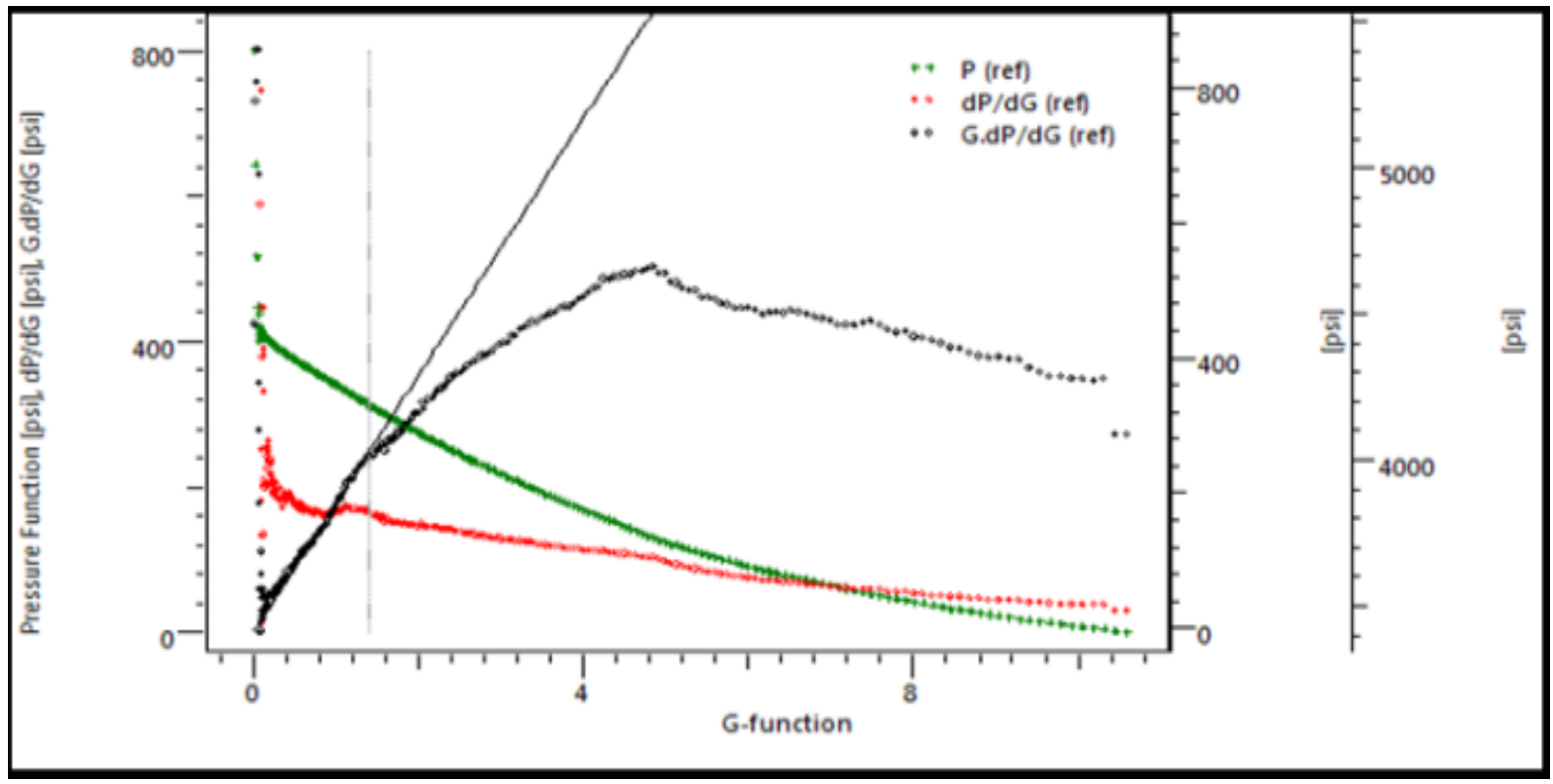

Figure 21 G- Function Plot

Table 15 After-Closure Analysis Results.

\begin{tabular}{|l|c|l|c|}
\hline Start of linear flow, Hrs. & 0.6 & Far field mobility, md/cp & 671 \\
\hline End Linear Flow, Hrs. & 1.3 & Flow Capacity “ $\mathrm{KH}^{\prime}$, md.ft & 675 \\
\hline Start of radial flow, Hrs. & 2.7 & Permeability, $\mathrm{md}$ & 37.5 \\
\hline Reservoir initial pressure & 3227 & Fracture half length , $\mathrm{ft}$ & 57 \\
\hline
\end{tabular}




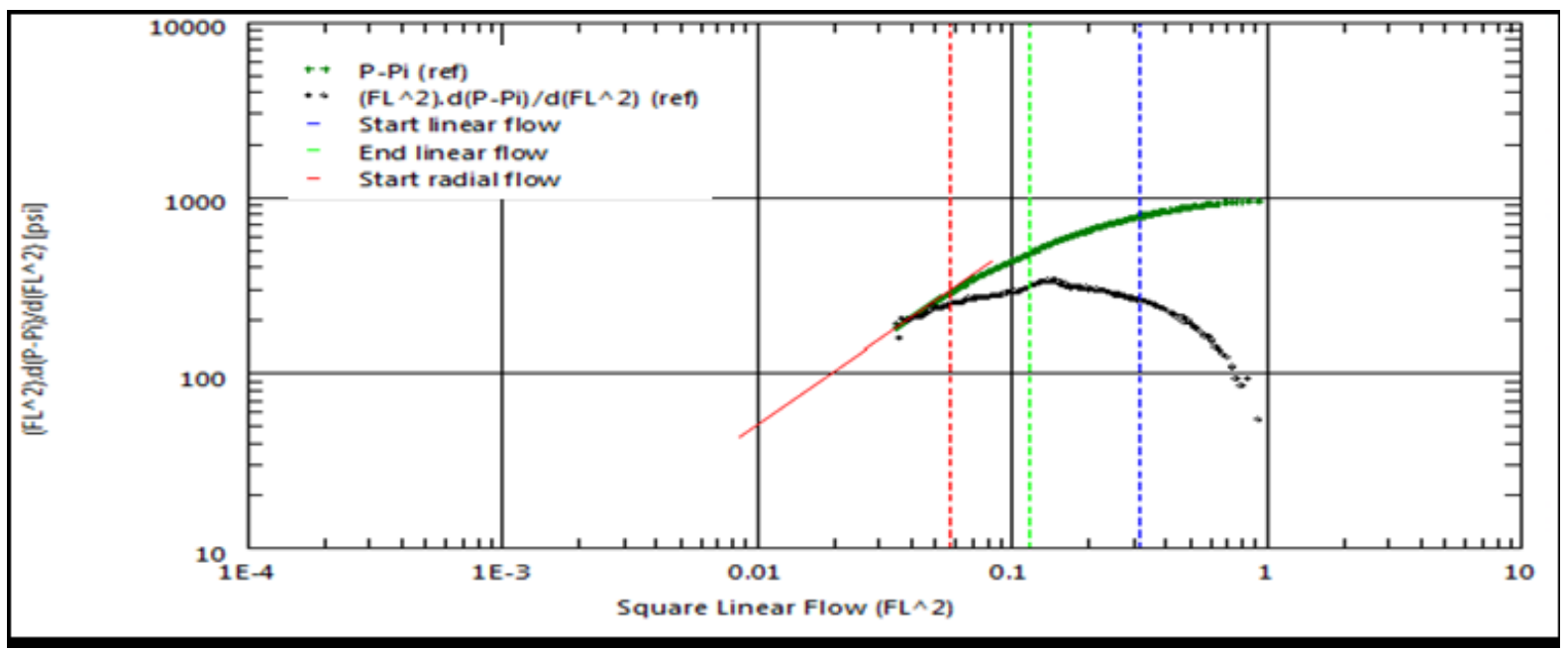

Figure 22 Log-Log Plot.

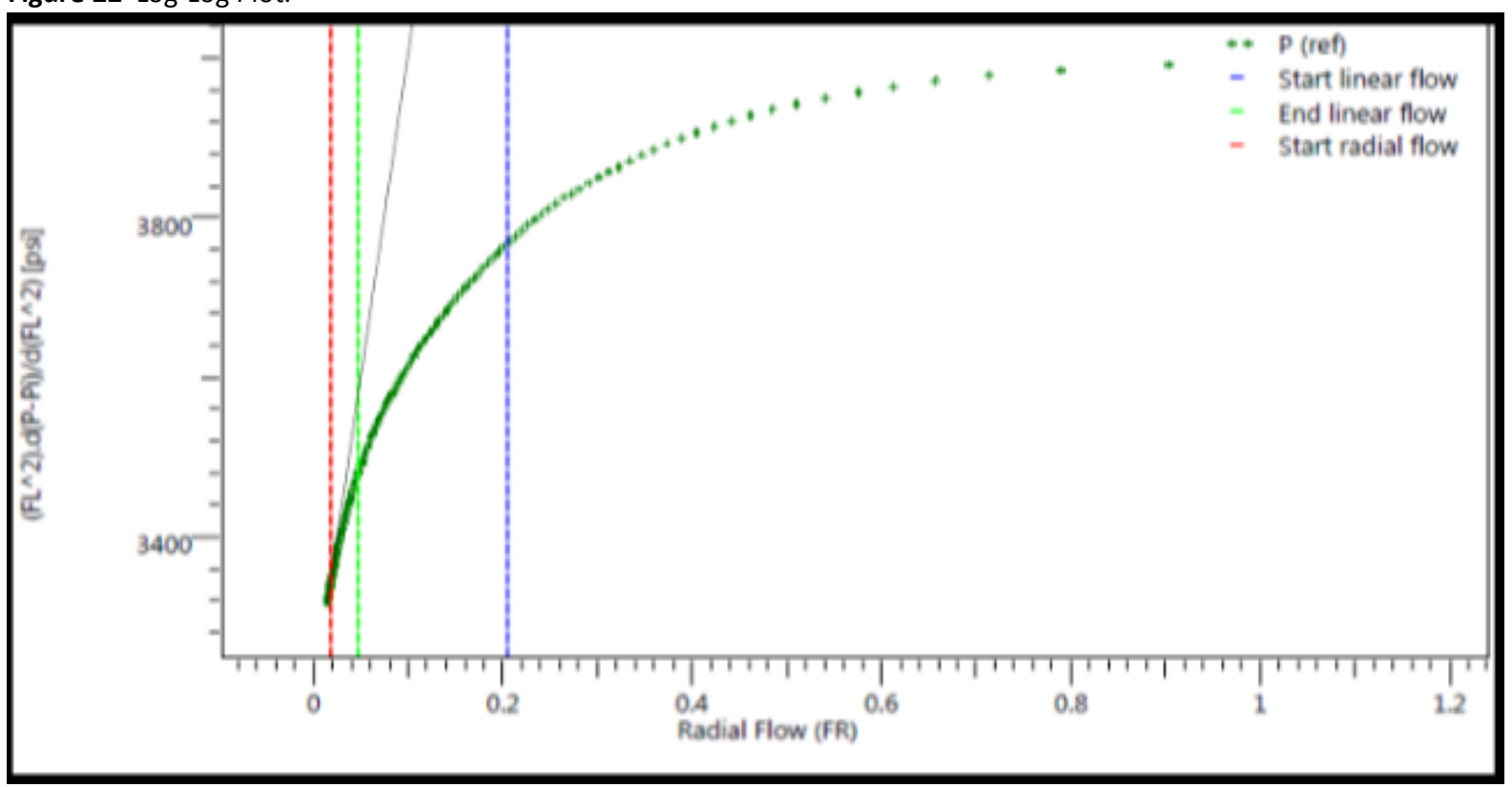

Figure 23 FR Plot.

\section{REFERENCES}

[1] Tarek Ahmed, and Paul D. McKinney." Advanced Reservoir Engineering" Chapter 1: Well Testing Analysis (2005).

[2] L.P. DAKE Paul." fundamentals of reservoir engineering" Chapter 7: The constant terminal rate solution of radial diffusivity equation and its application to oil well testing (1998).

[3] John Michaels, Mike Moody, Than Shwe "Advances In Wireline Formation Testing". SPWLA, Paris, France (1995).

[4] K.G. Nolte,: "Determination of Fracture Parameters from Fracture Pressure Decline". SPE 8341 Sept. 1979.

[5] K.G. Nolte,: "Fracture design Considerations Based on Pressure Based on Pressure Analysis" paper SPE 10911 May 1982

[6] Said Benelkadi/Sonatrach Inc., and Djebbar Tiab/U. of Oklahoma,: "Reservoir Permeability Determination Using After-Closure Period Analysis of Calibration Tests" paper SPE 70062 May 2001.

[7] K.G. Nolte, SPE, Dowell, J.L. Maniere, SPE, Dowell, and K.A. Owens, SPE, TexacolTrinmar,: “After-Closure
Analysis of Fracture Calibration Tests" paper SPE 38676 Oct 1997.

[8] G.LeBlanc, E. Gunasan, J-L. Boutaud de la Combe, V. Jaffrezic, TOTAL E\&P , SPE,: “Reservoir Characterization Using Injection test After-Closure Analysis:Field Case History in a Depleted Oil Recovery" paper SPE 128052 Feb 2010.

[9] I.M. Mohamed, R.A. Nasralla, M.A. Sayed, M. Marongiu-Percu, and C.A. Ehlig-Economides/Texas A\&M University: "Evaluation of After-Closure Analysis Technique for Tight and Shale Gas Formation " SPE, Texas, USA Jan 2011.

[10] K.G. Nolte, SPE, Dowell, J.L. Maniere, SPE, Dowell, and K.A. Owens, SPE, TexacolTrinmar,: "New Type Curve Analysis Removes Limitations of Conventional AfterClosure Analysis of DFIT Data After-Closure Analysis of Fracture Calibration Tests" paper SPE 168988 April 2014.

[11] Michael J. Economides and Kenneth G. Nolte. "Reservoir Stimulation, third edition". Chapter Nine: Fracture Evaluation Using Pressure Diagnostics (2000).

[12] Mike Mayerhofer "DFIT (Diagnostic Fracture Injection Test)", SWPLA Meeting by Halliburton (2012). 